\title{
A PSICOLOGIA SOCIAL DE THEODOR ADORNO NA PRODUÇÃO BRASILEIRA (1984-2015)
}

\author{
LA PSICOLOGÍA SOCIAL DE THEODOR ADORNO EN LA PRODUCCIÓN \\ BRASILEÑA (1984-2015) \\ THE SOCIAL PSYCHOLOGY OF THEODOR ADORNO IN BRAZILIAN \\ PRODUCTION (1984-2015)
}

http://dx.doi.org/10.1590/1807-03102016v28n3p537

Rodrigo Siqueira Câmara e Kety Valéria Simões Franciscatti

Universidade Federal de São João Del Rei, São João Del Rei/MG, Brasil

\section{RESUMO}

Este artigo apresenta parte de uma pesquisa que procurou iluminar uma tradição brasileira de pesquisa em Psicologia Social, alicerçada na teoria de Theodor Adorno. Seu objetivo foi identificar e discutir referências e apropriações dessa teoria, em especial sua proposta para a Psicologia Social, por pesquisadores brasileiros entre 1984 e 2015. Através da análise da produção científica, foram encontrados 197 artigos, dos quais foi realizada uma análise temática de 87, caracterizados como da Psicologia, com base nas seguintes categorias: estudos sobre dominação e violência social (24); estudos sobre o indivíduo e a formação cultural (14); estudos sobre indústria cultural, propaganda e consumo (11); estudos sobre ciência, metodologia e debates teóricos (17); estudos sobre educação (13); e estudos sobre arte e estética (8). Os resultados indicam uma presença significativa e crescente dessa perspectiva em Psicologia Social no Brasil e a ampliação, por parte dos pesquisadores, do seu escopo de reflexão e atuação.

Palavras-chave: Teoria Crítica da Sociedade; Psicologia Social; Psicologia Crítica; Adorno.

\section{RESUMEN}

Este artículo es parte de un estudio que buscó iluminar una tradición brasileña de investigación en Psicología Social, basado en la teoría de Theodor Adorno. Su objetivo fue identificar y analizar las referencias y apropiaciones de esta teoría, en particular su propuesta de Psicología Social, por investigadores brasileños entre 1984-2015. Mediante el análisis de la literatura científica, se encontró 197 artículos, y se llevó a cabo un análisis temático de 87, de psicología, basado en las categorías: estudios de dominación social y la violencia (24); estudios sobre la formación individual y cultural (14); estudios sobre industria cultural, publicidad y consumo (11); Los estudios de ciencia, metodología y debates teóricos (17); estudios sobre educación (13); y estudios de arte y estética (8). Los resultados indican una presencia significativa y creciente de esta perspectiva en Psicología Social en Brasil y la expansión, por los investigadores, del alcance de la suya reflexión y acción.

Palabras clave: Teoría Crítica de la Sociedad; Psicología Social; Psicología Crítica; Adorno.

\begin{abstract}
This article presents part of a study that sought to illuminate a Brazilian tradition of research in Social Psychology, based on Theodor Adorno's theory. Its aim was to identify and discuss references and appropriations of Adorno's theory, particularly its proposal for Social Psychology, by Brazilian researchers between 1984 and 2015. Through the analysis of scientific literature, 197 articles were found, and a thematic analysis was carried out in 87 of those, characterized as belonging to Psychology, based on the categories: studies of social domination and violence (24); studies on the individual and cultural formation (14); studies on cultural industry, advertising and consumption (11); studies on science, methodology and theoretical debates (17); studies on education (13); and studies on art and aesthetics (8). The results indicate a significant and growing presence of this perspective in Social Psychology in Brazil and the expansion, by the researchers, of its scope of reflection and action.
\end{abstract}

Keywords: Critical Theory of Society; Social Psychology; Critical Psychology; Adorno. 


\section{Introdução}

Este artigo tem por objetivo apresentar, de maneira sintética, parte dos resultados de uma pesquisa de mestrado que procurou lançar luz sobre uma determinada tradição brasileira de investigação em Psicologia Social, que tem produzido conhecimentos a partir da Teoria Crítica da Sociedade da Escola de Frankfurt, mais especificamente, com base na teoria de Theodor W. Adorno. A ênfase, neste recorte, é para a análise temática que foi realizada. Segundo o que pôde ser constatado, essa tradição remonta às décadas de 70 e 80 , com maior expressão a partir dos anos 90 , em uma tendência de crescimento presente até os dias atuais.

\section{Notas sobre a Psicologia Social no Brasil}

Para melhor compreender os determinantes objetivos que possibilitaram a emergência de uma Psicologia Social no Brasil com base na teoria de Adorno, torna-se importante traçar uma breve caracterização histórica e teórica da constituição dessa disciplina. Por meio de tal caracterização, é possível iluminar algumas das condições históricas que engendraram diferentes perspectivas de Psicologia Social no Brasil.

Segundo Lane (1984), no cenário internacional da Psicologia Social na década de 50, predominavam duas tendências principais: uma ligada ao pragmatismo norte-americano, em um viés adaptacionista; outra fundamentada na tradição filosófica europeia, marcada pela reconstrução do mundo pós-guerra. Para descrever essas duas tendências em Psicologia Social, pode ser utilizada a clássica divisão entre as perspectivas psicológica e sociológica. A primeira, conforme Bernardes (2013), centraliza as explicações sobre os fenômenos sociais a partir dos indivíduos; a segunda, por outro lado, tem sua atenção voltada para os processos e fenômenos que emergem da totalidade social. Essas duas perspectivas não se diferenciam apenas em termos de ênfase e conteúdo, mas também, e principalmente, no que tange à dimensão epistemológica - e, por conseguinte, metodológica - de suas investigações. Ao passo que na tendência psicológica a orientação teórico-metodológica é fundamentada no positivismo e na tradição experimental, na tendência sociológica há uma maior diversidade metodológica e influência de diferentes matrizes teóricas (Álvaro \& Garrido, 2003).

Enquanto a perspectiva psicológica de Psicologia Social teve seu desenvolvimento mais pronunciado na América do Norte, principalmente nos EUA, a perspectiva sociológica teve seu desenvolvimento mais marcante em solo europeu (Ferreira, 2010). Porém, essas considerações devem ser relativizadas, pois, como mostram Álvaro e Garrido (2003), a Psicologia Social sociológica se desenvolveu também nos EUA, principalmente com a Escola de Chicago. Além disso, podem ser lembrados os trabalhos de George Herbert Mead que, apoiados em uma perspectiva materialista - ainda que não a do materialismo histórico dialético -, não podem ser tão facilmente classificados como pertencentes às perspectivas psicológicas ou sociológicas. Em relação ao continente europeu, há que se considerar, também, que surgiram diferentes expressões de Psicologia Social, desde as tendências francesas e inglesas, mais claramente da perspectiva sociológica, como Moscovici e Taijfel, até tendências materialistas, dificilmente classificáveis somente nessa perspectiva, como os filósofos russos Vygostky, Leontiev e Luria, assim como os próprios autores frankfurtianos.

Para entender as primeiras produções em Psicologia Social no Brasil, é importante situá-las nesse contexto internacional, que se manteve em tal pêndulo durante muitas décadas, ora mais voltado ao estudo do indivíduo, ora ao estudo da sociedade, com o objetivo de investigar sua relação. No Brasil, até os anos 50 e 60, a Psicologia Social teve uma forte adesão às tendências norte-americanas, importando tanto as teorias e modelos metodológicos dessa perspectiva, como as concepções sociais que subjazem a esses modelos. Assim, o papel que coube à Psicologia em geral e à Psicologia Social, até esse período, foi o de alinhamento ao contexto social em que emergiu, contribuindo para a manutenção de uma visão de mundo que sustentava a ideologia dominante. Segundo Lacerda (2013), a Psicologia no Brasil nasceu associada às classes dominantes, buscando junto a elas sua legitimidade social. Nesse sentido, contribuiu para a consolidação do projeto burguês de modernização do país, baseado em um modelo de capitalismo dependente, que, no contexto mundial, submete os países do chamado "terceiro mundo" aos interesses dos países industrializados.

Esse cenário, atrelado a uma necessidade de legitimação da Psicologia enquanto ciência nos moldes tradicionais, contribuiu para que a Psicologia desenvolvida nos EUA se tornasse, até meados dos anos 50, hegemônica, inclusive no Brasil (Lane, 1984). No campo da Psicologia Social, a corrente da Psicologia Social psicológica é a vertente dessa Psicologia norteamericana que, integrada à sociedade americana em ascensão, contribuiu para a manutenção de sua 
ideologia dominante, imperialista e de dominação material e cultural.

A partir dos anos 60, no ensejo tanto da atmosfera de transformações sociais e políticas, que caracterizou essa década, quanto desse cenário de dominação e hegemonia americana, começa a se desenhar o que viria ser denominado, posteriormente, de "crise da psicologia social" (Álvaro \& Garrido, 2003; Bernardes, 2013; Ferreira, 2010; Lane, 1984; Leme, 2012; Molon, 2001). Essa crise se manifestou como um conjunto de críticas à Psicologia Social psicológica, no que tange aos mais diversos aspectos. Por um lado, havia uma crítica à dimensão metodológica que submetia toda investigação aos ditames do método científico importado das ciências naturais; por outro, havia uma crítica às teorias, concepções, consequências e relevâncias sociais dessa Psicologia Social (Lane, 1984). Além disso, foram feitas críticas do ponto de vista político dessa perspectiva, que contribuía para a manutenção de relações de poder e opressão. Tais críticas foram realizadas, em parte, por psicólogos ligados à tradição da Psicologia Social sociológica europeia e também por psicólogos sociais da América Latina, como Silvia Lane e Martin Baró, sendo que as críticas políticas foram mais acentuadas por estes últimos (Lane, 1984).

No Brasil, essas críticas repercutiram e permitiram a formulação de uma crítica própria à Psicologia Social dominante, mais explicitamente, nos anos 70 e 80 (Molon, 2001; Prado, 2011), sob as condições sociais do golpe militar de 1964, que implantou uma ditadura que perdurou até 1985. Para Lacerda (2013), o golpe militar significou tanto uma reação conservadora das elites dominantes às ameaças das lutas operárias e camponesas quanto uma forma de integração do Brasil no sistema econômico mundial enquanto um capitalismo dependente. Segundo Antunes (2012), após o golpe, fortaleceramse as concepções individualizantes da Psicologia, que contribuíram para a precarização da formação - e, pode-se acrescentar, da atuação - em Psicologia.

A partir desses determinantes começaram a surgir as primeiras experiências e trabalhos de crítica à Psicologia hegemônica e de constituição de uma Psicologia Social comprometida com a realidade latino-americana e também brasileira. Esse movimento tem sido chamado de Psicologia Social Crítica (Álvaro \& Garrido, 2003; Ferreira, 2010) e, mais recentemente, de Psicologia Crítica (Carvalho \& Dunker, 2006; Lacerda, 2013). Ambas expressões correspondem a uma variedade muito grande de tendências em Psicologia Social, mas que parecem coincidir no que diz respeito à crítica à Psicologia de base positivista.
A terminologia Psicologia Crítica, embora, ao que parece, corresponda ao mesmo movimento indicado pela Psicologia Social Crítica, é ainda pouco utilizada. Para Lacerda (2013), diferentes nomes têm sido utilizados para denominar os trabalhos dessa Psicologia Crítica, como Psicologia Institucional, Psicologia da Libertação, Psicologia do Oprimido, Psicologia Marxista, Psicologia Sócio-histórica, entre outros. Álvaro e Garrido (2003) identificam diferentes correntes teóricas que influenciam a Psicologia Social Crítica na América Latina, tais como a Psicanálise, a Teoria Crítica da Escola de Frankfurt, estudos sobre Representação Social, o Socioconstrucionismo, a Análise do Discurso.

É digno de nota que em parte do material consultado sobre a história da Psicologia Social no Brasil (Almeida, 2012; Ferreira, 2010; Lane, 1984; Molon, 2001; Prado, 2011) não há referências aos teóricos da Escola de Frankfurt enquanto marcos teórico-metodológicos presentes na Psicologia Social Crítica no contexto brasileiro, enquanto que nos estudos consultados que empregam a terminologia de Psicologia Crítica (Carvalho \& Dunker, 2006; Lacerda, 2013,) a influência da Teoria Crítica da Sociedade é mencionada. Embora ainda não se possa afirmar nada conclusivo nesse sentido, é possível que o reconhecimento da Teoria Crítica da Sociedade, enquanto uma importante referência para o campo da Psicologia Social no Brasil, tenha maior expressão junto à tradição que tem utilizado a terminologia Psicologia Crítica. Para ambos os casos, a referência central é Theodor Adorno e o seu trabalho "A personalidade autoritária", desenvolvido nos anos 50 em colaboração com outros autores.

\section{A Psicologia Social de Theodor W. Adorno}

O que se sugere como uma Psicologia Social de Adorno tem como referência o que ele nomeia, em alguns textos - como, por exemplo, "Sobre a relação entre Sociologia e Psicologia" (1955/2015b) e "Observações sobre política e neurose" (1954/2015a) -, como uma Psicologia Social analiticamente orientada, ou seja, uma Psicologia Social orientada pela apropriação da Psicanálise freudiana. A proposição de um campo de investigação nesses termos levanta um questionamento que, em um primeiro momento, pode ter a aparência de uma simples questão de nomenclatura, mas que, no entanto, remete a uma outra questão mais central e determinante na produção do conhecimento, ultrapassando o sujeito que nomeia e o método que o possibilita: o próprio objeto. Desse modo, portanto, cabe discutir o porquê da própria 
distinção entre a Psicologia em geral e Psicologia Social. Em relação a essa distinção, Freud (2011) critica a oposição entre a Psicologia individual e a Psicologia Social, ou das massas: "na vida psíquica do ser individual, o outro é via de regra considerado enquanto modelo, objeto, auxiliador e adversário, e portanto a psicologia individual é também, desde o início, psicologia social, num sentido ampliado, mas inteiramente justificado" (p. 10).

Certamente, esse posicionamento de Freud veicula um inegável conteúdo de verdade. Não é possível conceber o indivíduo se não a partir das relações que estabelece com os seus semelhantes. Esta concepção se apresenta como progressista em relação às perspectivas que, durante muito tempo (e ainda presente nos dias atuais), centralizam no próprio indivíduo sua realização, tomando-o como autossuficiente. Essas perspectivas tiveram um fértil solo de desenvolvimento com a emergência do liberalismo, na medida em que possibilitavam uma visão (ideológica) de homem que estava de acordo com as demandas econômicas que se apresentavam no momento do estabelecimento do capitalismo enquanto modo de produção.

Nesse contexto, Horkheimer e Adorno (1956/1973) ressaltam a importância das teorias tanto da Filosofia como da Sociologia, que abalaram essa crença absoluta no indivíduo, demonstrando como esse só existe como produto social, ou mediado socialmente. Antes de o indivíduo se referir a si mesmo, ele é um semelhante para os outros homens, mesmo que não tenha consciência disso. Somente a posteriori é que lhe será possibilitada a diferenciação em relação aos outros, por meio da relação com esses. Assim, a unidade social fundamental não é o indivíduo, mas a própria relação social, mútua determinação estabelecida na participação e na comunicação necessárias para a convivência com outros. Nesse sentido, quando se considera o lugar central das determinações objetivas na própria emergência do indivíduo enquanto fenômeno histórico, não seria realmente coerente a nomeação de uma Psicologia individual que não fosse também Psicologia Social, ou vice-versa.

No entanto, se por um lado o aprofundamento possibilitado pela teoria psicanalítica freudiana permite reconhecer a indissociabilidade entre indivíduo e sociedade, a partir do reconhecimento das marcas da sociedade naquilo que mais fundamentalmente caracteriza esse indivíduo, por outro, Freud, ao não reconhecer que tais determinações objetivas são também históricas - inclusive, conforme Adorno, ao ponto de postular ideias tais como a da atemporalidade do inconsciente -, acaba por elevar cisões da própria realidade ao estatuto de características fundamentais do indivíduo. Para Adorno (1955/2015b), essa "diferença de temporalidade entre inconsciente e consciente é ela própria um estigma do desenvolvimento social contraditório. No inconsciente sedimenta-se aquilo que no sujeito sempre fica para trás e que tem que pagar as contas do progresso social e do esclarecimento" ( $p$. 95).

Em decorrência do estado em que se encontra o indivíduo nas condições do capitalismo tardio - o qual, em sua integração massiva, diminui os espaços de mediação social e fortalece o poder da sociedade frente à impotência do indivíduo - e, portanto, de uma primazia acentuada do todo em relação à parte, torna-se relevante e não equivocada a proposição de uma Psicologia Social, uma vez que "a primazia da sociedade é reforçada retrospectivamente por aqueles processos psicológicos típicos, sem que aí se anuncie equilíbrio ou harmonia entre os indivíduos e a sociedade" (Adorno, 1966/2015c, p. 129).

Assim, uma Psicologia Social que reconheça o estado atual de impotência do indivíduo assume, também, o lugar de uma Psicologia que demarca um posicionamento crítico em relação àquelas psicologias (sociais) individualistas, que tão fortemente se fizeram presentes na produção do conhecimento no campo da Psicologia no momento em que Adorno propôs suas formulações sobre a ciência psicológica, como parte dos seus modelos de crítica da cultura. Podese argumentar que tais modelos críticos ainda são atuais, uma vez que essas psicologias com ênfase individualista assumem, nos dias de hoje, um grande espaço no cenário acadêmico, embora sob novas roupagens, que agora reduzem o indivíduo às suas características neurológicas, químicas, biológicas ou ainda comportamentais.

Não deve se considerar, no entanto, que toda a história do conhecimento tenha ressaltado somente tal perspectiva individualista. Isto seria uma inverdade. Falso também seria conceber que perspectivas que reconhecem o indivíduo constituído a partir das relações sociais tenham se iniciado com Freud ou Adorno. Quando se discute a proposição de uma Psicologia Social analiticamente orientada por Adorno, não significa que esse campo de estudos tenha sido fundado por ele, mas que surgiu mesmo das demandas objetivas de reflexão sobre seu objeto de estudo, a formação subjetiva no contexto da irracionalidade objetiva do capitalismo tardio. Segundo Adorno (1954/2015a), esse campo de estudos tem seu início com o próprio Freud (2011), em especial no texto "Psicologia das massas e análise do eu", que, para Adorno (1954/2015a), desencanta a discussão a 
respeito da psicologia das massas ou da psicologia de grupo, bem como dos fenômenos coletivos que se observam nessas formações quando "desdobra os modos de comportamento grupal semelhantes à hipnose a partir da vida pulsional dos que se unem em um grupo" (p. 192). Com um novo olhar sobre os fenômenos coletivos, por um lado, Freud avança na compreensão desses fenômenos, não mais atribuindo a eles um caráter de "natureza coletiva sui generis" (p. 192), ou seja, discutidos de um ponto de vista de uma coletividade abstrata que não encontra respaldo concreto em seus integrantes individuais. Além disso, avança em um outro sentido, embora possivelmente não intencionalmente, quando, "através deste procedimento, a teoria de Freud forneceu expressão a uma situação social em que precisamente a formação de grupo tem como pressuposto a atomização e alienação dos seres humanos" (p. 192).

Posteriormente, nessa mesma perspectiva de investigação, de uma Psicologia Social analiticamente orientada, encontram-se os trabalhos do próprio Instituto de Pesquisa Social com participação direta ou indireta de Adorno. Os trabalhos que são lembrados pelo próprio Adorno (1954/2015a) são "Estudos sobre Autoridade eFamília", de 1936, que procurou investigar as relações entre dinâmica social e mecanismos psíquicos com base na teoria psicanalítica, no que diz respeito aos comportamentos em relação à autoridade; e também "A personalidade autoritária", de 1950, que procurou investigar as relações entre diferentes ideologias políticas e estruturas psíquicas. Nesse sentido, é importante ressaltar que, para o estudo de fenômenos psicossociais - como os traços autoritários e também dos demais processos envolvidos nas novas configurações psíquicas requisitadas pelo capitalismo tardio -, é necessário o reconhecimento das várias determinações que constituem os fenômenos e os objetos na realidade, o que, por sua vez, implica no tensionamento entre diferentes disciplinas do conhecimento. Essa discussão, no que diz respeito à Psicologia Social, perpassa, principalmente, a relação entre a Sociologia e Psicologia.

De acordo com Adorno (1955/2015b), quando se discute a relação entre Sociologia e Psicologia como disciplinas científicas, antes do impulso à síntese, devese perguntar, em primeiro lugar, sobre a separação real entre sociedade e indivíduo. Como discutido anteriormente, não há como conceber o indivíduo sem remetê-lo à sua constituição social e, nesse sentido, afirmar a priori a separação entre indivíduo e sociedade é ideologia, no sentido de encobrir a potencialidade histórica de uma relação não antagônica. No entanto, o que Adorno ressalta é a importância de se reconhecer a contradição que acompanha essa questão. Embora, mesmo que a sociedade produza indivíduos alienados à sua condição social e isso ainda seja uma produção social, há que se reconhecer que, efetivamente, existe uma separação, um antagonismo entre o indivíduo e a sociedade, que historicamente foi se transformando nas diferentes formas de dominação, até as formas atuais do capitalismo tardio. Desse modo, a produção do conhecimento no âmbito das relações entre Sociologia e Psicologia não pode ignorar que a separação é da realidade e, portanto, reside no próprio objeto de estudo.

Ao pontuar essas questões, Adorno (1955/2015b) critica os posicionamentos que desconsideram as contradições da objetividade social na tentativa de integrar Teoria Social e Psicologia, ressaltando, nessa crítica, algumas das proposições teóricas dos revisionistas da Psicanálise. Essas proposições, segundo Adorno, deslocavam a ênfase do conteúdo real da contradição entre sociedade e indivíduo para a divisão do trabalho acadêmico e o desenvolvimento metodológico. O que esses ignoram, no entanto, é que a própria divisão do trabalho científico é reflexo da contradição do objeto cindido na realidade. A possibilidade da relação entre uma teoria da subjetividade e a Teoria Social que Adorno defende está sustentada na tentativa de reconhecer a contradição que as determina e a descontinuidade que isso acarreta no desenvolvimento de cada uma delas. A potencialidade do confronto entre essas disciplinas encontra-se atrelada à capacidade de, ao divergirem, iluminarem contradições que transcendam as suas fronteiras disciplinares.

A descontinuidade entre Psicologia e Sociologia expressa, portanto, a diferenciação do desenvolvimento teórico-conceitual de cada uma, na medida em que a natureza mesma dos problemas em que estão interessadas, embora produtos da mesma sociedade, também se constitui de maneira diferente. Segundo Adorno (1955/2015b, p. 75): "somente através da determinação da diferença, e não através de conceitos ampliados, sua relação será expressa de forma adequada. A verdade do todo reside na unilateralidade, não na síntese pluralista". O exemplo de Freud, nesse caso, é bastante ilustrativo. Conforme Adorno salienta, Freud, em sua tentativa de encontrar no interior do indivíduo os elementos mais propriamente psíquicos na investigação do inconsciente, acaba, paradoxalmente, por encontrar as marcas sociais nos indivíduos como, por exemplo, a questão da interdição do incesto, do complexo de Édipo, da internalização da imago paterna e a questão da horda primeva. É nesse sentido que Adorno entende a Psicanálise freudiana 
como a única Psicologia que seriamente investiga as condições subjetivas da irracionalidade objetiva.

Diferentemente do que pôde ser observado em parte do desenvolvimento posterior da Psicanálise, como no caso dos revisionistas, para Adorno (1955/2015b), a teoria freudiana, na sua radicalidade e até certa intransigência, possibilita um mergulho na particularidade que ilumina algo do todo unilateral. Isso não retira as críticas de Adorno a Freud, quando argumenta que a tentativa deste de entender a Sociologia como Psicologia aplicada, como no caso dos temas acima discutidos, é ideologia. E é ideologia principalmente porque, ao tomar o inconsciente $\mathrm{e}$ a vida psíquica como invariáveis, naturaliza aquilo que é histórico e mascara sua determinação social. Por outro lado, também é falsa a tentativa inversa de adaptação dos conceitos e princípios psicanalíticos às demandas da ordem social, como pôde ser observado na ego psychology ao retirar a ênfase na sexualidade e na vida pulsional, uma das principais contribuições da Psicanálise de Freud, e colocá-las sob uma Psicologia de reforçamento do eu, altamente adaptada ao sistema econômico e à repressão sexual que o caracteriza.

Desse modo, a proposta de uma Psicologia Social de Adorno está perpassada por essas discussões que dizem respeito à relação mesma da Psicologia com o seu objeto. Enquanto Psicologia Social, tem o papel de eleger como um dos seus objetos de estudo os comportamentos irracionais das formações de massa. Esses foram amplamente desenvolvidos no contexto dos regimes totalitários nazifascistas e dizem respeito às condições históricas, de infraestrutura e de superestrutura, que eclodiram nesses períodos, de forma bastante manifesta, e que permanecem ainda na base das sociedades pós-guerra, de forma talvez ainda mais acentuada do que anteriormente, embora em grande medida ainda latentes. Uma questão que deve ser levantada diz respeito ao modo como esses traços fascistas - que podem ser observados nos dias atuais, tanto do ponto de vista institucional como do ponto de vista de suas apropriações subjetivas, que, por sua vez, estão na base e servem à manutenção do sistema vigente - são integrados no contexto das democracias capitalistas e, mais especificamente, das formações capitalistas típicas de países em desenvolvimento, como o Brasil.

\section{Método}

A análise da produção científica, estudo de metaciência, é uma importante parte do trabalho científico que possibilita obter um panorama a respeito da produção de conhecimentos em uma determinada área. De acordo com Witter (1999), esses estudos são importantes pois, por meio desse tipo de análise, pode-se delimitar a profundidade e amplitude dos conhecimentos científicos em um determinado contexto, bem como identificar tendências, autorias, o como, o por quê, e, também, recuperar algo da história de um determinado campo do conhecimento e iluminar suas problemáticas atuais. Para essa análise, recorremos aos parâmetros propostos por Lima e Mioto (2007): temático, linguístico, cronológico e a definição das fontes.

Em relação ao parâmetro temático, foram estabelecidos para compor o corpus de pesquisa todos os artigos que, no interior do campo da produção de conhecimentos no Brasil e no limite da abrangência dos indexadores, fizeram referência no título, palavraschave ou resumo à teoria de Theodor Adorno. Em relação aos parâmetros linguístico e cronológico, não houve uma restrição específica, uma vez que as próprias bases de dados online por si só já são uma limitação, principalmente para a busca e acesso a textos antigos.

Em relação às fontes, foram consultados textos no formato artigo, além dos websites das revistas científicas e os currículos Lattes dos pesquisadores. Foram realizadas buscas, entre a última semana do mês de maio e a primeira semana do mês de junho do ano de 2015, para composição de um corpus preliminar de análise, em quatro indexadores: Scielo, Pepsic, Indexpsi e Lilacs. Foram utilizadas as conjugações de termos "Adorno" (todos os campos) "and not Adorno" (campo autor). Essas buscas resultaram em um total de 197 artigos; destes, 87 foram caraterizados e analisados como produção da Psicologia, ou seja, de autores brasileiros com formação, graduada ou pós-graduada, e/ou atuação no âmbito da Psicologia, abarcando o período de 1984 a 2015. A discussão que se propõe neste recorte restringe-se à exposição da análise temática com base nos resumos, palavraschave e título.

\section{Resultados e discussão}

Com base em leituras sucessivas do material, foram criadas seis categorias, segundo as temáticas dos artigos, que procuram mostrar algo da amplitude observada na produção. É importante destacar que a linha que divide essas categorias é tênue e somente é utilizada para a análise segundo os objetivos desta pesquisa, ainda que se tenha consciência das limitações impostas a tal tipo de categorização. Também é necessário ressaltar que as categorias propostas não se pretendem autoexcludentes e nem homogêneas. As 
categorias propostas foram: Estudos sobre dominação e violência social ( 24 pesquisas $-27,6 \%$ do total); Estudos sobre o indivíduo e a formação cultural (14 pesquisas - 16,1\% do total); Estudos sobre indústria cultural, propaganda e consumo (11 pesquisas 12,6\% do total); Estudos sobre ciência, metodologia e debates teóricos (17 pesquisas - 19,5\% do total); Estudos sobre educação (13 pesquisas - 14,9\% do total); e Estudos sobre arte e estética (8 pesquisas - 9,2\% do total). No "Anexo A - Referências do corpus de análise", estão listadas e especificadas por categorias as referências dos 87 artigos analisados.

Segundo o que foi levantado, a maior parte das investigações (cerca de três quartos) é constituída por reflexões teóricas. A predominância dos estudos teóricos, provavelmente, está associada à natureza mesma das investigações conduzidas, que têm proposto problemas de pesquisas para os quais os estudos teóricos são o meio privilegiado. No entanto, a quantidade de investigações empíricas é também bastante razoável, com cerca de um quarto da produção, entre estudos empíricos e experimentais. Entre os métodos propostos nesses estudos, encontram-se a etnografia, a história oral, a pesquisa-intervenção e também estudos que não nomearam especificamente os seus métodos, bem como propostas de tipologias e estudos que recorreram à metodologia experimental.

A menor presença de estudos empíricos pode indicar o momento da maior parte dos pesquisados desse campo no Brasil, isto é, a compreensão de que antes de se conduzir uma investigação empírica é importante o aprofundamento teórico necessário. Essa tendência está em concordância com a proposição de Adorno, segundo a qual, dentro das condições da sociedade atual, deve ser resguardada uma relação indireta entre teoria e práxis, para que não se conduzam práticas de adesão a uma realidade opressiva e à produção de conhecimentos que justifiquem as contradições sociais - ideologia. Nesse sentido, o espaço da teoria, respaldada por uma base material, resguarda a possibilidade de resistência frente às tendências afirmativas que atendem diretamente aos interesses de reprodução da sociedade atual e suas relações de dominação.

Com base no que pôde ser observado na análise temática realizada, existe uma variedade considerável de temáticas e problemáticas que têm sido objeto de investigação nos estudos analisados. De um modo geral, a grande maioria das pesquisas pode ser inserida no campo da Psicologia, com especial ênfase na Psicologia Social, ainda que alguns desses artigos também possam ser caracterizados como de outras áreas. É digno de nota que, entre os trabalhos que nomearam o seu campo de investigação no interior da Psicologia, com exceção das referências à Psicanálise, somente existem referências à Psicologia ou à Psicologia Social ou, ainda, às duas. Em nenhum dos resumos analisados foi observada a menção a qualquer outra subárea da Psicologia. Da mesma forma, é relevante salientar que um dos textos mais citados nas referências bibliográficas dos artigos foi "Sobre a relação entre a Sociologia e a Psicologia" (1955/2015b), que é o ensaio no qual Adorno discute sua proposta de Psicologia Social. Assim, é possível considerar que, embora em alguns casos não haja referência direta a essa questão, a maior parte desses trabalhos pertence à Psicologia Social, em termos de conteúdo e objeto/objetivo de investigação.

Em relação à primeira categoria, "Estudos sobre dominação e violência social", a maioria das investigações foi realizada com base no estudo de fenômenos mais específicos. Estão contempladas nessas investigações, tanto empíricas como teóricas, as temáticas do preconceito, do fascismo/autoritarismo, da dominação do corpo, da justiça/criminalidade, do contexto do trabalho, da participação social/ movimentos sociais, bem como situações específicas de violência. Também foram conduzidas, em menor escala, investigações sobre a dominação e violência social de um ponto de vista mais amplo, sem se deter, necessariamente, a algum fenômeno mais específico, discutindo questões como ética e moral, inversão entre meios e fins e violência e subjetividade.

O fato de essa categoria ter sido a mais expressiva no conjunto da produção pode estar relacionado à questão de que uma das problemáticas centrais para os autores frankfurtianos, e para Adorno em especial, é justamente o progresso da dominação que permanece atrelado ao desenvolvimento da sociedade. Essa dominação que os autores denunciaram está na base mesma da sociedade e se manifesta nos diversos âmbitos da vida social e particular. Desse modo, é possível entender que, dentro dessa temática, os autores das pesquisas selecionadas investigaram diferentes formas de dominação e de violência, na maior parte dos estudos, propondo análises sobre os processos de violência e de dominação da sociedade, como também sua relação com o indivíduo ou, ainda, propondo análises sobre objetos e situações mais específicos. Entre esses, estão estudos com objetos semelhantes aos investigados pelos autores frankfurtianos, tais como: autoritarismo e fascismo; preconceito e trabalho. Contudo, também foram realizados estudos procurando entender outros fenômenos como, por exemplo, a participação em movimentos sociais, o trote universitário, a disfunção erétil, a administração 
pública, a inclusão social e a pesquisa-intervenção. Também pesa sobre essa expressividade a centralidade da discussão sobre a dominação na obra de Adorno, principalmente em "Dialética do esclarecimento" (1947/1985), em parceria com Horkheimer, que foi o trabalho mais citado nas produções e na maioria das categorias. Esse fato, por sua vez, indica que é possível que ainda recaia sobre a leitura de Adorno no Brasil um peso muito forte para essa obra específica.

No que diz respeito à categoria "Estudos sobre a formação cultural e o indivíduo", estão reunidas investigações, nesse caso todas teóricas, que discutem, em sua maioria, a Psicologia e a Psicologia Social, problematizando o lugar dessas disciplinas no contexto do esclarecimento e na formação do indivíduo, bem como a proposta da Psicologia Social de Adorno. Foram conduzidas, também, pesquisas nas temáticas da liberdade, da resistência, da ética, do sofrimento e do suicídio em suas relações com a mediação social e a formação do indivíduo. A discussão sobre a formação do indivíduo, que está estreitamente relacionada com a dominação social, é também uma das questões centrais para Adorno na sua crítica da sociedade. Nos estudos analisados, foram discutidas, principalmente, as questões relacionadas à impotência e fragilidade do indivíduo, no contexto atual da sociedade, frente ao poder cada vez maior da totalidade social que, cada vez mais, integra na sua racionalidade instrumentalizada todos os âmbitos da vida social, pública e privada. Os estudos ressaltam também como cada vez menos a totalidade social tem necessitado das instâncias de mediação social para a sua reprodução, uma vez que tem agido quase diretamente sobre os indivíduos que precisam regredir psicologicamente para aderir à ideologia - que se mantém também por meio da satisfação inconsciente de impulsos irracionais nos indivíduos.

A quantidade significativa de pesquisas que têm investigado essas questões, ainda que não necessariamente a partir da descrição de dados empíricos - inclusive, pela natureza dessas investigações - pode indicar que o contexto brasileiro, como parte do sistema capitalista, que é, necessariamente, internacional, tem reproduzido as mesmas condições dentro de suas especificidades, o que também tem exigido tais renúncias e deformações dos indivíduos.

Em relação à categoria "Estudos sobre indústria cultural, propaganda e consumo", estão englobadas as pesquisas que discutem a indústria cultural sob diferentes aspectos, para a análise da ideologia, de propagandas, do consumo, da educação, da tecnologia, bem como do conformismo/passividade e de sua influência sobre o comportamento. Essas pesquisas também se preocupam, de um modo geral, em ressaltar a atualidade do conceito de indústria cultural para o entendimento da sociedade contemporânea. É bastante notável a quantidade de trabalhos que se propuseram a discutir a indústria cultural ou entender fenômenos à luz desse conceito, quando se observa o conjunto da produção.

Certamente, isso traz a marca que especificamente o conceito de indústria cultural teve na recepção do pensamento de Adorno no Brasil. Embora realmente tal conceito seja importante nas discussões de Horkheimer e Adorno (1947/1985) para pensar o lugar e o papel da ideologia na manutenção da dominação, além de pertinente para discutir problemáticas do contexto brasileiro (como observado nas produções), é também importante que, de um modo geral, haja um reconhecimento de que a obra desses autores ultrapassa, em muito, o conceito de indústria cultural. Ademais, sua discussão está inserida na problemática da dialética do esclarecimento, sem a qual perde parte de seu sentido. Possivelmente por ter sido um dos primeiros conceitos dos frankfurtianos a serem discutidos no Brasil, em um momento privilegiado para o seu reconhecimento no contexto social brasileiro, foi sujeito a muitas leituras diferentes e também a leituras reducionistas, que acabaram por associar muito enfaticamente Adorno e Horkheimer ao conceito de indústria cultural, setorizando sua obra e ignorando suas reais contribuições.

A categoria "Estudos sobre ciência, metodologia e debates teóricos" abrange, em sua maioria, estudos que promovem discussões teóricas e conceituais entre Teoria Crítica e Psicanálise. Essas pesquisas procuraram realizar aproximações e tensionamentos teóricos entre essas correntes, discussões sobre as apropriações dos frankfurtianos em relação à Psicanálise, discussões sobre a clínica e a técnica psicanalíticas e a investigação de fenômenos mais específicos à luz de diferentes teorias. É importante ressaltar que a Psicanálise é uma referência presente com maior expressão no conjunto das categorias, sendo a principal referência citada pelos artigos. Essas informações podem ser entendidas, principalmente, como já pontuado anteriormente, pelo lugar que a Psicanálise freudiana ocupa no projeto frankfurtiano e, especificamente, no pensamento de Adorno. Desse modo, as discussões que o autor propõe para a Psicologia Social, do ponto de vista das configurações psicológicas, têm como referência o recurso às categorias psicanalíticas naquilo que elas trazem da constituição desse objeto na realidade. Esse recurso, no entanto, não presume uma assunção plena por parte 
de Adorno das propostas freudianas, mas sim, como exposto, uma apropriação crítica que envolve um exame minucioso dos limites da Psicanálise.

Também pôde ser observado, entre as produções analisadas dessa categoria, um movimento de tensionamento teórico entre o pensamento de Adorno e outros autores, como Vygotsky, Foucault e John Thompson, bem como a respeito do debate da tradição da Teoria Crítica, envolvendo, principalmente, Habermas. Esses esforços teóricos de confronto entre teorias de diferentes autores, observado nessa produção nacional, têm se limitado a autores do contexto internacional, sem referências diretas a autores brasileiros de outras perspectivas teóricas. No que diz respeito ao debate sobre a tradição da Teoria Crítica ressaltada nos estudos analisados, cabe salientar que existem diferentes perspectivas sobre essa questão: uma que ressalta a ruptura de Habermas com o projeto frankfurtiano inicial e outra que propõe que esse autor, na verdade, representa uma continuidade dessa tradição. No contexto brasileiro, essa discussão se manifesta em propostas de Psicologia Social que se apoiam, mais especificamente, na obra de Habermas e que representam uma minoria no material analisado.

Em relação às questões da metodologia e da ciência, as pesquisas analisadas propõem discussões sobre as potencialidades dos métodos empíricos para a Psicologia Social com base em Adorno, discutindo os métodos de "A personalidade autoritária" e o método da História Oral. Sobre a ciência, foram discutidas a questão da pesquisa administrada no contexto acadêmico brasileiro e a produção de conhecimentos de um modo geral. Essas discussões epistemológicas, teórico-metodológicas, sempre acompanharam o desenvolvimento dos trabalhos de Adorno e são imprescindíveis na sua proposta de Psicologia Social.

Em relação aos "Estudos sobre educação", é possível perceber um amplo movimento de articulações da teoria de Adorno para pensar questões da Educação e da Educação no Brasil. De um modo geral, as pesquisas procuraram tratar dos aspectos da realidade escolar e da formação à luz de diferentes conceitos e discussões de Adorno, como a indústria cultural, a semiformação cultural, os tabus sexuais e a experiência. Algumas pesquisas ainda procuraram investigar, mais especificamente, fenômenos psicossociais do preconceito em relação à deficiência e ao bullying, que se manifestam no cotidiano escolar, orientados pelas pesquisas teóricas e empíricas de Adorno, procurando entender esses fenômenos para além do campo da Educação e remetendo-os ao antagonismo social. Por fim, também foram realizadas pesquisas que procuraram discutir a Educação na perspectiva de uma educação emancipatória e, também, sua relação com a tecnologia.

A questão da formação foi sempre central para Adorno. No entanto, é perceptível que essa temática, mais especificamente em relação à Educação, foi um dos principais interesses do autor no final dos anos 60. Nesse período, Adorno produziu um material considerável sobre o tema, principalmente a partir de conferências, palestras e participações em programas de rádio, no qual discutiu problemáticas concretas da Educação na Alemanha e da Educação de uma forma geral, entendida, pelo autor, como uma necessária educação contra a barbárie e uma educação para a emancipação. Nesse momento mais tardio de sua obra, no conhecido texto sobre Auschwitz, Adorno (1995) propõe, ante a impossibilidade, nas atuais condições sociais, de alteração substancial da ordem objetiva determinante na manutenção da dominação -, que os esforços de uma Teoria Crítica devem se dirigir para o estudo da formação e da subjetividade.

Os "Estudos sobre arte e estética" representam a menor parte da produção, segundo as categorias elaboradas. No material que foi analisado, parte das pesquisas propuseram análises sobre a Arte e a Estética com foco nos estudos sobre a música, tanto discutindo trabalhos de Adorno sobre o tema como conduzindo investigações empíricas a respeito da limitação da consciência relacionada à indústria musical. Também foram realizadas investigações sobre a relação entre a Arte e as suas potencialidades/limitações para a formação do indivíduo, sobre a relação entre a técnica e a indústria cultural, bem como discussões sobre Estética em relação à cultura massificada.

Adorno, além do trabalho intelectual, possuía uma formação musical, de modo que seus interesses pela música e pela Estética de uma forma geral sempre estiveram presentes nas suas discussões teóricas, não desvinculadas de sua crítica da sociedade. A pouca representatividade desse enfoque nas produções analisadas não indica, contudo, que tal discussão é inexistente no Brasil - pelo contrário, existe uma produção razoável no país que enfatiza o debate acerca da Estética e da Filosofia da Arte, com base nos autores frankfurtianos -, mas sim que, possivelmente, essas discussões não foram suficientemente apropriadas pelo campo da Psicologia e seus pesquisadores.

\section{Considerações finais}

Em relação à tradição da Psicologia Social no Brasil, conforme foi apresentado e discutido, existem ainda poucas referências diretas à influência dos 
frankfurtianos sobre esse campo. No entanto, segundo pôde ser demonstrado por esta pesquisa, tal perspectiva de produção de conhecimentos em Psicologia Social existe no Brasil e está crescendo ao longo dos anos. A partir desse prisma, é necessário um posicionamento fundamental em relação à Psicologia, que ressalte seu caráter social e, desse modo, possibilite a crítica às Psicologias (sociais) que não reconheçam as condições atuais de impotência dos indivíduos ante a totalidade social. Conforme foi discutido, o momento da crise da Psicologia Social possibilitou a emergência de novas perspectivas - voltadas para as realidades latinoamericana e brasileira e para o compromisso com a transformação social - e configurou, também, uma perspectiva de Psicologia Social Crítica em oposição às tradicionais formas psicológicas e sociológicas dessa disciplina. Pensando a tradição de pesquisa aqui analisada, em que há o reconhecimento necessário do estudo da mediação social e da crítica social, podese considerar a perspectiva da Psicologia Social de Adorno como uma tentativa de superação daquelas tendências tradicionais de Psicologia Social.

No que diz respeito especificamente à proposta de Psicologia Social com base na teoria de Adorno, foi possível perceber, por meio da análise dessa produção nacional, que essa perspectiva tem encontrado, por um lado, um solo fértil para seu desenvolvimento e, por outro, para sua "atualização". Isto é, conforme foi observado nos artigos, os pesquisadores brasileiros que se fundamentam na Psicologia Social de Adorno têm alargado, em certa medida, os horizontes da proposta inicial do autor. Esse "alargamento" pode ser observado tanto nas temáticas que foram (e são) investigadas por esses pesquisadores no contexto nacional como pelas propostas metodológicas. O que pôde ser observado é que, além da proposta inicial de Adorno na sua Psicologia Social analiticamente orientada - que estaria mais voltada ao estudo dos comportamentos irracionais característicos das formações de massa, de regressão psicológica e adesão à violência e que puderam ser observados claramente no nazifascismo - , os pesquisadores nacionais têm se voltado, também, ao estudo de outros fenômenos, não tão diretamente relacionados a essas questões. É claro, deve-se pontuar que a diversidade de temas não se refere a uma diversidade verdadeira, no sentido da diferença/ diferenciação, almejada pela formação cultural, e sim uma diversidade na pobreza de experiências, unilateralmente impostas no capitalismo tardio em um contexto dependente. O que aqui se indica como diversidade é a amplitude de objetos de estudo a que têm se voltado esses pesquisadores, exigência daquilo que se mantém e se modifica na realidade atual, ou seja, a necessidade de se investigar o movimento do objeto na contemporaneidade - as velhas/novas marcas da violência impressas pela sociedade nos indivíduos, que podem corresponder a situações de não experiência em contexto brasileiro.

Nesse sentido, a Psicologia Social analisada nesta pesquisa, fundamentada na obra de Adorno, tem reafirmado o compromisso com a transformação social e, também, tem se posicionado criticamente às condições de violência e opressão que marcam o contexto social mais amplo e, especificamente, o contexto brasileiro.

Defende-se, portanto, que essa apropriação e certa atualização da teoria de Adorno pela Psicologia Social no Brasil, no período analisado - e que é o nosso momento atual -, deve ser entendida à luz das modificações do contexto mais amplo da sociedade. Essas modificações dizem respeito, cada vez mais, a uma maior integração de características dos regimes totalitários fascistas no contexto das democracias neoliberais - estrutura econômico-política em pleno desenvolvimento no mundo e no Brasil - que deixa suas marcas nos indivíduos.

Como não houve uma transformação real nas condições que engendram os tipos de violência fascista e os traços subjetivos autoritários, esses foram integrados ao conjunto da sociedade, no sentido de sua própria manutenção e funcionalidade. Se isso pôde ser observado de forma bastante clara com base nas análises de Adorno no período pós-guerra, principalmente nos EUA (suposto exemplo de democracia), também pode servir de referência para pensar essas questões no contexto brasileiro que, após a reabertura política pós-ditadura militar, tem se integrado cada vez mais a esse tipo de democracia, cujas bases são ainda a da violência e da opressão social, como pode se ver, de modo cada vez mais manifesto, nas expressões de ódio e de indiferença tão presentes no atual contexto brasileiro.

Ressalta-se, no entanto, a necessidade de aprofundar essa investigação direcionando a análise para os textos integrais dos artigos, para além dos aspectos aqui analisados. Somente nessa dimensão, outras considerações sobre a apropriação e a atualidade dos modelos críticos, que a teoria de Adorno pode proporcionar, estarão disponíveis. Tal investigação permitiria a análise se, por ventura, parte desses estudos se encontraria enrijecida no sentido da crítica, reificada, perdendo aquilo mesmo que a teoria deveria defender, ou, na confirmação das tendências aqui indicadas, se esses estudos têm contribuído, de fato, para a denúncia e contenção da barbárie que ainda é característica central da nossa organização social. 


\section{Referências}

Almeida, L. P. (2012). Para uma caracterização da psicologia social brasileira. Psicologia: Ciência e Profissão, 32(n. spe.), 124-137.

Adorno, T. W. (1995). Educação após Auschwitz. In Palavras e sinais (M. H. Ruschel, Trad., pp. 104-123). Petrópolis, RJ: Vozes.

Adorno, T. W. (1954/2015a). Observações sobre política e neurose. In Ensaios sobre Psicologia Social e Psicanálise (V. Freitas, Trad., pp. 191-198). São Paulo: UNESP. (Original publicado em 1954)

Adorno, T. W. (1955/2015b). Sobre a relação entre Sociologia e Psicologia. In Ensaios sobre Psicologia Social e Psicanálise (V. Freitas, Trad., pp. 71-127). São Paulo: UNESP. (Original publicado em 1955)

Adorno, T. W. (1966/2015c). Pós-escrito. In Ensaios sobre Psicologia Social e Psicanálise (V. Freitas, Trad., pp. 127135). São Paulo: UNESP. (Original publicado em 1966)

Álvaro, J. L.\& Garrido,A. (2003). Psicología social: perspectivas psicológicas y sociológicas. Madrid: Editorial McGraw Hill.

Antunes, M. A. M. (2012). A Psicologia no Brasil: um ensaio sobre suas contradições. Psicologia: Ciência e Profissão, 32(n. spe.), 44-65.

Bernardes, J. D. S. (2013). História. In P. A. Guareschi, M. D. G. C. Jacques, M. N. Strey, T. M. G. Fonseca, N. M. G. Bernardes, \& S. A. Carlos (Orgs.), Psicologia Social Contemporânea (pp. 19-35). Petrópolis, RJ: Vozes.

Carvalho, J. D. \& Dunker, C. I. L. (2006). Critical psychological approaches in Brazil: When, where, why. Annual Review of Critical Psychology, 5, 305-312. Acesso em 15 de abril, 2015, em https://thediscourseunit.files.wordpress. com/2016/05/arbrazil-arcp-5.doc

Ferreira, M. C. (2010). A Psicologia Social contemporânea: principais tendências e perspectivas nacionais e internacionais. Psicologia: Teoria e Pesquisa, 26(n. spe.), 51-64.

Freud, S. (2011). Psicologia das massas e análise do eu. In Psicologia das massas e análise eu e outros textos (19201923), (P. C. Souza, Trad., Vol. 15, pp. 9-101, Edição Standard Brasileira das Obras Completas de Sigmund Freud). São Paulo: Companhia das Letras.

Lacerda, F. (2013). Capitalismo dependente e a psicologia no Brasil: das alternativas à psicologia crítica. Revista Teoria y crítica de la psicología (online), 3, 216-263.

Lane, S. T. (1984). A Psicologia Social e uma nova concepção do homem para a Psicologia. In W. Codo \& S. Lane (Orgs.), Psicologia Social: o homem em movimento (pp. 10-19). São Paulo: Brasiliense.
Leme, M. A. (2012). Caminhos e descaminhos da Psicologia Social. Psicologia: Teoria e Pesquisa, 5(3), 269-273.

Lima, T. C. \& Mioto, R. C. T. (2007). Procedimentos metodológicos na construção do conhecimento científico: a pesquisa bibliográfica. Revista Katálysis, 10(2), 37-45.

Horkheimer, M. \& Adorno, T. W. (1956/1973). Indivíduo. In Temas Básicos da Sociologia (A. Cabral, Trad., $2^{\mathrm{a}}$ ed., pp. 45-60). São Paulo: Cultrix. (Original publicado em 1956)

Horkheimer, M. \& Adorno, T. W. (1985). Dialética do esclarecimento: fragmentos filosóficos (G. A. Almeida, Trad.). Rio de Janeiro: Jorge Zahar. (Original publicado em 1947)

Molon, S. I. (2001). A Psicologia Social abrapsiana. Interações, 12(6), 41-68.

Prado, K. (2011). Para uma arqueologia da Psicologia Social. Psicologia \& Sociedade, 23(3), 464-468.

Witter, G. P. (1999). Metaciência e leitura. In Leitura: textos e pesquisas (pp. 13-22). Campinas, SP: Alínea.

\section{Agradecimento}

À CAPES pela concessão de bolsa de estudos (DS) durante a realização do mestrado.

Submissão em: 16/05/2016

Revisão em: 15/07/2016

Aceite em: 03/08/2016

Rodrigo Siqueira Câmara é graduado em Psicologia pela Universidade Federal de São João del Rei (2014). Mestre em Psicologia pela Universidade Federal de São João del

Rei (2016).

Endereço: Rua Anália Esteves Ribas, 301. Jardim Alvorada. Ouro Preto/MG, Brasil. CEP 35400-000.

E-mail: rodrigoasd@bol.com.br

Kety Valéria Simões Franciscatti é professora permanente do Programa de Pós-graduação em Psicologia, pesquisadora do Laboratório de Pesquisa e Intervenção Psicossocial e professora Associada do Departamento de Psicologia da Universidade Federal de São João Del-Rei (PPGPSI/LAPIP/DPSIC/UFSJ). Possui graduação em Formação de Psicólogo e Licenciatura em Psicologia pela Universidade Metodista de Piracicaba, mestrado (1998) e doutorado (2005) em Psicologia (Psicologia Social) pela Pontifícia Universidade Católica de São Paulo.

E-mail: kety.franciscatti@gmail.com 


\section{Anexo A. Referências do corpus de análise}

\section{Estudos sobre dominação e violência social}

Calderoni, E. (2004). A irracionalidade da racionalidade técnica: uma crítica às inversões entre fins e meios. Psicologia Argumento, 22(36), 57-66.

Caniato, A. M. P. (1999). A impunidade na sociedade e no direito: implicações psicossociais. Revista do Departamento de Psicologia da UFF, 11(2/3), 9-26.

Caniato, A. M. P., Rodrigues, A., Silva, J., Quilice, K., Santos, L., Corazza, L., Castro, M., Reis, N., Sales, O., Fernandez, P., \& Borges, S. (2002). Phenix: a ousadia do renascimento da subjetividade cidadã. Psicologia \& Sociedade, 14(2), 95-132.

Caniato, A. M. P., Abeche, R. P. C., \& Bastian, S. A. H. (2008). A violência na vida cotidiana de famílias albergadas: seus sofrimentos e conformação social. Fractal: Revista de Psicologia, 20(1), 89-118.

Caniato, A. M. P. (2008). Violências e subjetividades. O indivíduo contemporâneo. Psicologia \& Sociedade, 20(1), 16-32.

Caniato, A. M. P. \& Rodrigues, S. M. (2012). A construção psicossocial da competição: o engano na cumplicidade de uma falsa vida. Psicologia \& Sociedade, 24(1), 23-35.

Carone, I. (2002). Fascismo on the air: estudos frankfurtianos sobre o agitador fascista. Lua Nova: Revista de Cultura e Politica, 55-56, 195-217.

Chaves, E. (2003). O fascismo como um "sistema paranóico": a "psicanálise do anti-semitismo" na dialética do esclarecimento. Pulsional Revista de Psicanálise, 16(176), 25-33.

Crochík, J. L. (2005). Notas sobre a dicotomia corpo-psique. Interações, 10(19), 103-122.

Crochík, J. L. (2005). Preconceito: relações com a ideologia e com a personalidade. Estudos de Psicologia (Campinas), 22(3), 309-319.

Erthal, T. C. (1984). Personalidade e mudança de atitude. Arquivos Brasileiros de Psicologia, 36(3), 90-98.

Figueiredo, G. C. \& Pinto, J. M. R. (2014). Acampamento e assentamento: participação, experiência e vivência em dois momentos da luta pela terra. Psicologia \& Sociedade, 26(3), 562-571.

Lastória, L. A. C. N. (2001). Ethos sem ética: a perspectiva crítica de T.W. Adorno e M. Horkheimer. Educação \& Sociedade, 22(76), 63-75.

Lhullier, L. (1992). Psicologia do autoritarismo: uma abordagem preliminar. Psico, 24(2), 141-157.

Gomes, N. F. (2006). Ações educacionais no combate à violência: contribuições da Psicanálise e da Teoria Crítica. Psicologia para América Latina, 6. Acesso em 20 de setembro, 2015, em http://pepsic.bvsalud.org/ scielo.php?script=sci_arttext\&pid=S1870-350X2006000200008\&lng=pt\&nrm=iso\&tlng $=$ pt

Gomes, N. F. (2014). Ética na administração pública: desafios e possibilidades. Revista Brasileira de Administração Pública, 48(4), 1029-1050.

Gomide, A. P. A. (2013). Notas sobre suicídio no trabalho à luz da Teoria Crítica da Sociedade. Psicologia: Ciência e Profissão, 33(2), 380-395.

Massola, G. M. (2007). Mimese e crime em Adorno e Horkheimer: comentário sobre o "Fragmento de uma teoria do criminoso". Estudos de Psicologia (Natal), 12(2), 133-139.

Nakamura, M. R. S. (2010). Construção de diálogos: uma experiência de abordagem em Psicologia Social em projeto cultural. Pesquisas e Práticas Psicossociais, 4(2), 172-181.

Ramos, C. (2004). A dominação do corpo no mundo administrado: uma questão para a Psicologia Social. Psicologia: Ciência e Profissão, 24(1), 56-63.

Ramos, C. (2006). O "ressentimento do guerreiro": reflexões sobre corpo e educação a partir do pensamento de Theodor Adorno e da Psicanálise. Interações, 11(21), 9-28.

Rodrigues, O. M. (1993). A busca da "personalidade autoritária" na disfunção erétil. Revista Brasileira de Sexualidade Humana, 4(1), 63-74.

Schewinsky, S. R. (2004). A barbárie do preconceito contra o deficiente-todos somos vítimas. Acta fisiátrica, 11(1), 7-11.

Zuin, A. A. S. (2002). O trote no curso de pedagogia e a prazerosa integração sadomasoquista. Educação \& Sociedade, 23(79), 234-254. 


\section{Estudos sobre o indivíduo e a formação cultural}

Ardans, O. (1996). De cascas e chispas: reflexões em torno do conceito de redenção a partir do aforismo 153 de Minima Moralia. Interações, 1(2), 139-152.

Batista, S. S. S. (2001). O projeto interdisciplinar da Teoria Crítica: a história e a Psicologia. Psicologia USP, 12(1), 121-133.

Carone, I. (1991). De Frankfurt à Budapest: os paradoxos de uma Psicologia de base marxista. Psicologia USP, 2(1-2), 111-120.

Chaves, J. C. (2011). O conceito de liberdade na dialética negativa de Theodor Adorno. Psicologia \& Sociedade, $22(3), 438-444$.

Crochík, J. L. (1998). Os desafios atuais do estudo da subjetividade na Psicologia. Psicologia USP, 9(2), 69-85.

Crochík, J. L. (2001). A resistência e o conformismo da mônada psicológica. Psicologia \& Sociedade, 13(2), $18-33$.

Crochík, J. L. (2008). T.W. Adorno e a Psicologia Social. Psicologia \& Sociedade, 20(2), 297-305.

Crochík, J. L. (2010). A forma sem conteúdo e o sujeito sem subjetividade. Psicologia USP, 21(1), 31-46.

Franciscatti, K. V. S. (2002). “À felicidade na liberdade ou à felicidade na ausência de liberdade”. Psicologia \& Sociedade, 14(1), 123-140.

Moraes, A. L. (2006). Sobre a negatividade do conceito de indivíduo em Adorno: a resistência possível. Psicologia USP, 17(3), 127-144.

Maia, A. F. (1998). Apontamentos sobre ética e individualidade a partir da Minima Moralia. Psicologia USP, 9(2), 151-177.

Rocha, A. P. \& Franciscatti, K. V. S. (2009). Suicídio e liberdade de vontade: possibilidades de individuação na sociedade industrial. Pesquisas e Práticas Psicossociais, 4(1), 17-25.

Ramos, C. (1999). Elementos para uma psicologia do sujeito cativo. Psicologia USP, 10(2), 11-34.

Silva, P. F. (2015). Psicologia Social de Adorno: resistência à violência do mundo administrado. Psicologia \& Sociedade, 27(1), 35-46.

\section{Estudos sobre indústria cultural, propaganda e consumo}

Abeche, R. P. C. \& Ferreira, A. G. (2010). "Ficando" sem ficar: a astúcia da indústria cultural. Psico, 41(3), 340-345.

Abeche, R. P. C., Trevizan, R. D., \& Peres, A. C. A. (2011). Indústria cultural: líder glamourizado que sujeita indivíduos à condição de massa. Revista Polis e Psique, 1(2), 73- 90.

Caniato, A. M. P., Cesnik, C. C., \& Rodrigues, S. M. (2012). A captura da subjetividade pela violência simbólica da indústria cultural: da submissão à culpabilidade dos indivíduos. Psicologia USP, 23(4), 661-681.

Gomide, A. P. A. (2011). As "propagandas do horror" e os fenômenos de massa contemporâneos. Psicologia em Estudo, 16(4), 571-580.

Morais, R. C., Pascual, J. G., \& Severiano, M. F. V. (2011). "Apaixonados por carros como todo brasileiro" (?) - Reflexões frankfurteanas sobre a indústria cultural contemporânea. Estudos e Pesquisas em Psicologia, 11(3), 873-897.

Ramos, C. (2008). Consumismo e gozo: uma compreensão de ideologia entre T.W. Adorno e J. Lacan. Psicologia USP, 19(2), 199-212.

Rodrigues, S. M. \& Caniato, A. M. P. (2012). Subjetividade e indústria cultural: uma leitura psicanalítica da cumplicidade dos indivíduos com a lógica da mercadoria. Psicologia em Revista, 18(2), 227-246.

Silva, N. \& Lirio, D. R. (2006). A recodificação pós-moderna da perversão. Sobre a produção do comportamento de consumo e sua gramática libidinal. Ágora, 9(1), 65-78.

Zanolla, S. R. S. (2007). Indústria cultural e infância: estudo sobre formação de valores em crianças no universo do jogo eletrônico. Educação \& Sociedade, 28(101), 1329-1350.

Zuin, A. A. S. (2001). Sobre a atualidade do conceito de indústria cultural. Cadernos Cedes, 21(54), 9-18.

Zuin, A. A. S. (2006). A vingança do fetiche: reflexões sobre indústria cultural, educação pela dureza e vício. Educação \& Sociedade, 27(94), 71-90. 


\section{Estudos sobre ciência, metodologia e debates teóricos}

Alves, D. G. (2003). Adorno e a instabilidade do sujeito. Pulsional Revista de Psicanálise, 16(176), 5-9.

Amaral, M. G. T. (2000). O mal-estar na psicanálise entrelaçado com a regressão da subjetividade contemporânea: o que a desmedida do amor passional e o funcionamento-limite têm a dizer? Revista Brasileira de Psicanálise, 34(2), 319-343.

Amaral, M. G. T. (2001). Adolescentes sem limites ou funcionamentos-limite diante de uma existência que exige a demissão do sujeito? Revista Brasileira de Psicanálise, 35(4), 1001-1021.

Bianchetti, L. \& Zuin, A. A. S. (2013). O intelectual universitário e seu trabalho em tempos de "pesquisa administrada". Educação em Revista, 28(3), 55-75.

Carone, I. (2001). Teoria Crítica e pesquisa empírica na Psicologia. Psicologia \& Sociedade, 13(2), 9-17.

Checchia, M. A. (2005). O sujeito e a adolescência. Encontro, 9(11), 80-85.

Crochík, J. L. (2004). Apontamentos sobre o narcisismo da perspectiva da Teoria Crítica da Sociedade. Jornal de Psicanálise, 37(68), 193-222.

Gomide, A. P. A. (2011). Psicanálise e Teoria Social à luz da Teoria Crítica de Theodor W. Adorno. Psicologia: Ciência e Profissão, 31(1), 120-133.

Hilário, L. C. (2014). A potência da crítica: o problema da aporia em Habermas e seu destino em Adorno. Kriterion: Revista de Filosofia, 55(129), 309-329.

Hilário, L. C. \& Cunha, E. L. (2012). Michel Foucault e a Escola de Frankfurt: reflexões a partir da obra crítica do poder, de Axel Honneth. Trans/Form/Ação, 35(3), 157-188.

Lima, A. B. (2003). Psicologia Social e mídia: notas para algumas reflexões metodológicas. Revista do Departamento de Psicologia da UFF, 15(1), 111-124.

Lima, A. F. (2011). Sobre a crítica de Jürgen Habermas ao projeto frankfurtiano: separação epistemológica ou continuidade de uma tradição? Estudos e Pesquisas em Psicologia, 11(1), 181-196.

Nunes, A. B. (1999). A razão esclarecida e a dessacralização da vida: considerações sobre o pensamento ocidental moderno. Encontro: Revista de Psicologia, 4,11-13.

Salgado, M. \& Franciscatti, K. V. S. (2014). A análise dos dados da História Oral: fundamentos para uma Psicologia Crítica. Estudos e Pesquisas em Psicologia, 14(1), 304-319.

Souza, M. R. (2011). O conceito de esclarecimento em Horkheimer, Adorno e Freud: apontamentos para um debate. Psicologia \& Sociedade, 23(3), 469-476.

Souza, M. R. \& Birman, J. (2014). Ética e estética da alteridade em Horkheimer, Adorno e Freud: comentários a partir de "elementos do anti-semitismo" e "o inquietante". Psicologia \& Sociedade, 26(2), 251-260.

Zanolla, S. R. S. (2012). O conceito de mediação em Vigotski e Adorno. Psicologia \& Sociedade, 24(1), 5-14.

\section{Estudos sobre Educação}

Antunes, D. C. \& Zuin, A. A. S. (2008). Do bullying ao preconceito: os desafios da barbárie à educação. Psicologia \& Sociedade, 20(1), 33-42.

Barros, C. C. (2007). Reflexões sobre a formação de professores de Psicologia. Temas em Psicologia, 15(1), 33-39.

Batista, S. S. S. (2000). Teoria Crítica e teorias educacionais: uma análise do discurso sobre educação. Educação \& Sociedade, 21(73), 182-205.

Batista, S. S. S. (2011). Experiência e observação: de Rousseau ao Referencial Curricular Nacional para a Educação Infantil. Educação e Pesquisa, 37(4), 779-792.

Crochík, J. L., Casco, R., Ceron, M., \& Catanzaro, F. O. (2009). Relações entre preconceito, ideologia e atitudes frente à educação inclusiva. Estudos de Psicologia (Campinas), 26(2), 123-132.

Crochík, J. L., Ferrari, M. A. L. D., Hryniewicz, R. R., Barros, O. N. D., \& Nascimento, R. B. (2006). Preconceito e atitudes em relação à educação inclusiva. Psicologia Argumento, 24(46), 55-70.

Giordano, R. (2004). Políticas da Educação e sistemas filosóficos: a vontade da exclusão. Cadernos Cedes, 24(64), 329-344.

Lastória, L. A. C. N. (2003). Impasses éticos na educação hoje. Educação \& Sociedade, 28(83), 429-440. 
Maia, A. F. (1998). Notas sobre ideologia e educação. Interface-Comunicação, Saúde, Educação, 2(3), 23-34.

Medrano, E. M. O. \& Valentim, L. M. S. (2001). A indústria cultural invade a escola brasileira. Cadernos Cedes, 21(54), 69-74.

Sekkel, M. C., Zanelatto, R., \& Brandão, S. B. (2010). Uma questão para a educação inclusiva: expor-se ou resguardar-se? Psicologia: ciência e profissão, 30(2), 296-307.

Zuin, A. A. S. (2008). Tabus sexuais entre professores e alunos. Pro-Prosições, 19(2), 135-150.

Zuin, A. A. S. (2013). Copiar, colar e deletar: a Internet e a atualidade da semiformação. Pro-Posições, 24(3), 139-159.

\section{Estudos sobre arte e estética}

Amaral, M. G. T. (1998). A sublimação estética nos interstícios da cultura contemporânea. Revista Brasileira de Psicanálise, 32(2), 299-316.

Arreguy, M. E. (2015). Estéticas da diversão nos “mortos-vivos” contemporâneos. Psicologia USP, 26(1), 100107.

Carone, I. (2003). Adorno e a educação musical pelo rádio. Educação \& Sociedade, 24(83), 477-493.

Dadico, L. (2012). A “fisiognomia" do livro no estudo psicológico da leitura. Psicologia em Estudo, 17(4), 629-638.

Maia, A. F. (2000). Arte, técnica e indústria cultural. Interface-Comunicação, Saúde, Educação, 4(6), 21-38.

Maia, A. F. \& Antunes, D. C. (2008). Música, indústria cultural e limitação da consciência. Revista Mal-Estar e Subjetividade, 8(4), 1143-1176.

Pires, M. C. C. M. (2000). Criação e cultura de massa: algumas considerações a partir da música dos DJs. Psicologia Clínica, 12(2), 83-96.

Viana, C. M. J. \& Franciscatti, K. V. S. (2015). Impasses da natureza humana: semiformação e arte como anamnese da história. Psicologia \& Sociedade, 27(1), 13-23. 